\title{
Persepsi Petani terhadap Program Demonstrasi Area Budidaya Tanaman Sehat Padi (Studi Kasus di Kecamatan Polokarto Kabupaten Sukoharjo)

\author{
Farmers Perception Of Demonstration Area Program Of Healthy Rice Crop Cultivation (Case \\ Study In Polokarto, Sukoharjo)
}

Luthfi Agung Ardhianta, Retno Setyowati, Agung Wibowo

\author{
Program Studi Penyuluhan dan Komunikasi Pertanian Fakultas Pertanian \\ Universitas Sebelas Maret \\ J1. Ir. Sutami No.36 A Kentingan Surakarta 57126 Telp/Fax (0271) 637457 \\ Email: luthfiagungardhianta@student.uns.ac.id
}

\begin{abstract}
The objectives of the study were to assess, the perception of farmers on the program for demonstration area of healthy rice cultivation, examine the characteristics of the factors forming the perception of farmers participating in the program for demonstration area of healthy rice cultivation, analyze of the correlation between the factors forming perceptions farmers to demonstration healthy rice cultivation area program. The study used the method of descriptive by using survey techniques. The location was in Polokarto, Sukoharjo, taking 2 villages implementing the program. The population was the member farmers of the Pilangrejo farmer group and the Kenteng Farmer Group. The study used a proportional random sampling technique and respondents were taken as many as 60 farmers. The data in this study were presented with a Likert scale and to test the correlation used Spearman rank analysis and t-test. The results showed that, the factors forming perceptions were age, formal education, non-formal education, land area, income, experience, and motivation, Farmers' perceptions of the understanding, goals, benefits, and activities contained in the program demonstration area of healthy rice crop cultivation were good, There was a significant correlation between income and experience of farmers to the program demonstration area of healthy rice cultivation. Whereas age, formal education, non-formal education, land area, and motivation were not significantly related to farmers' perceptions of the program for the cultivation of healthy rice.
\end{abstract}

Keywords: Demontration Area, Farmers, Healthy Rice, Perception

\begin{abstract}
Abstrak: Penelitian ini bertujuan untuk, mengkaji persepsi petani terhadap program dem area budidaya tanaman sehat padi, mengkaji karakteristik faktor-faktor pembentuk persepsi petani peserta program dem area budidaya tanaman sehat padi, menganalisis hubungan antara faktor-faktor pembentuk persepsi petani terhadap program dem area budidaya tanaman sehat padi. Digunakan metode deskriptif dengan teknik survey pada penelitian ini. Lokasi yang dipilih sebagai lokasi penelitian adalah Kecamatan Polokarto Kabupaten Sukoharjo dengan mengambil 2 desa yang melaksanakan program. Populasi yang digunakan adalah petani anggota kelompok tani Pilangrejo dan Kelompok Tani Kenteng. Penelitian ini menggunakan teknik proportional random sampling dalam menentukan sample dan responden diambil sebanyak 60 petani. Data pada penelitian ini disajikan dengan skala likert dan untuk menguji hubungan digunakan analisis rank spearman dan uji $t$. Hasil penelitian menunjukkan bahwa, faktor pembentuk persepsi yaitu umur, pendidikan formal, pendidikan non formal, luas lahan, pendapatan, pengalaman dan motivasi, persepsi petani terhadap pengertian, tujuan, manfaat, dan kegiatan yang terkandung dalam program dem area budidaya tanaman sehat padi adalah baik, terdapat hubungan yang signifikan antara pendapatan dan pengalaman petani terhadap program dem area budidaya tanaman sehat padi. Sedangkan umur, pendidikan formal, pendidikan non formal, luas lahan dan motivasi tidak berhubungan signifikan terhadap persepsi petani terhadap program dem area budidaya tanaman sehat padi.
\end{abstract}

Kata Kunci: Dem Area, Padi Sehat, Persepsi, Petani 


\section{PENDAHULUAN}

Mewujudkan ketahanan pangan secara berkelanjutan menjadi isu dan agenda prioritas dalam pertemuan yang diselenggarakan berbagai negara dan lembaga internasional (Suryana, 2002). Salah satu tantangan dan permasalah di Indonesia adalah bagaimana petani mempertahankan kemampuan untuk menjamin produksi dan ketahan pangan bagi mereka dan bangsa mereka. Ditambah dengan pertumbuhan penduduk Indonesia yang setiap tahunnya terus meningkat. Dipastikan bahwa ketersediaan pangan merupakan hal yang krusial saat ini.

Campur tangan pemerintah Indonesia sangat besar dalam upaya peningkatan produksi dan stabilitas harga beras. Instruksi Presiden Republik Indonesia Nomor 5 Tahun 2011 tentang Pengamanan Produksi Beras Nasional dalam menghadapi Kondisi Iklim Ekstrim melalui Direktorat Perlindungan Tanaman Pangan, melaksanakan kegiatan dem area budidaya tanaman sehat padi. Program ini dikelola oleh kelompok tani/gabungan kelompok tani dan didampingi oleh petugas pusat dan daerah. Kegiatan dilaksanakan di daerah sentra produksi padi yang potensial/endemis OPT, antara lain Provinsi Aceh, Sumatera Utara, Sumatera Barat, Sumatera Selatan, Lampung, Jawa Barat, Jawa Tengah, DI Yogyakarta, Jawa Timur, Banten, Bali, Nusa Tenggara Barat, Kalimantan Selatan dan Sulawesi Selatan.

Jawa Tengah merupakan lumbung beras nasional kedua setelah Jawa Timur, dengan produksi sekitar 779 ribu ton dengan hampir setiap wilayah merupakan daerah potensi padi. Kabupaten Sukoharjo merupakan kabupaten terkecil kedua di Jawa Tengah, meski begitu Kabupaten Sukoharjo merupakan Kabupaten yang mampu mencetak surplus beras tertinggi di Jawa Tengah di tahun 2017 (Putra, 2018). Potensi Kabupaten Sukoharjo yang demikian menjadikan Kabupaten Sukoharjo sebagai pelaksana program Demonstrasi Area (yang selanjutnya disingkat dengan Dem Area) Budidaya Tanaman Sehat Padi yang bertempat di Kecamatan Polokarto. Data Badan Pusat Statistik tahun 2018 menunjukkan untuk luasan panen dan produksi padi sawah di Kecamatan Polokarto yaitu 6.674 ha dan 49.685 ton.
Sebuah keberhasilan suatu program bergantung dengan bagaimana persepsi petani terhadap Program Dem Area Budidaya Tanaman Sehat Padi itu sendiri, karena hakikatnya persepsi adalah proses penilaian seseorang terhadap obyek tertentu. Persepsi adalah pengalaman tentang objek, peristiwa dan hubungan yang diperoleh dengan menyimpulkan informasi dan menafsirkan pesan (Rakhmat, 2007) Mengingat keberhasilan program bergantung terhadap persepsi petani terhadap program, maka perlu dilakukan penelitian tentang persepsi petani terhadap program Dem Area Budidaya Tanaman Sehat Padi (Studi Kasus di Kecamatan Polokarto Kabupaten Sukoharjo). Tujuan dari penelitian ini adalah sebagai berikut, mengkaji persepsi petani terhadap program dem area budidaya tanaman sehat padi (studi kasus di Kecamatan Polokarto Kabupaten Sukoharjo), mengkaji karakteristik faktor-faktor pembentuk persepsi petani peserta program dem area budidaya tanaman sehat padi (studi kasus di Kecamatan Polokarto Kabupaten Sukoharjo), menganalisis hubungan antara faktor-faktor pembentuk persepsi petani terhadap program dem area budidaya tanaman sehat padi ( studi kasus di Kecamatan Polokarto Kabupaten Sukoharjo).

\section{METODE PENELITIAN}

Metode yang digunakan dalam penelitian ini adalah metode penelitian deskriptif. Teknik pengumpulan data yang digunakan dalam penelitian ini adalah teknik survei dengan menggunakan kuisioner. Lokasi yang dipilih adalah Kecamatan Polokarto Kabupaten Sukoharjo yang melaksanakan program dem area budidaya tanaman sehat padi. Program ini dikelola oleh kelompok tani Kenteng dan kelompok tani Pilangrejo. Populasi pada penelitian ini adalah petani yang tergabung dalam kelompok tani Kenteng dan kelompok tani Pilangrejo yang berjumlah 164 orang. Sampel pada penelitian ini ditentukan dengan teknik proportional random sampling, yang mana jumlah sampel tiap kelompok telah dihitung menggunakan rumus proporsi terlebih dahulu. Responden diambil sebanyak 60 petani diambil dari kedua kelompok tani, yaitu kelompok tani Kenteng sejumlah 29 orang dan kelompok tani Pilangrejo sejumlah 31 orang. Sumber data yang digunakan adalah data primer 
dan sekunder. Teknik pengumpulan data yang digunakan dalam penelitian ini adalah observasi yaitu pengamatan langsung untuk mendapatkan gambaran mengenai lokasi tempat penelitian, wawancara untuk mendapatkan data dan informasi, dan pencatatan yaitu mencatat data yang didapat dari responden ataupun instansi Data responden yang diperoleh akan dianalisis menggunakan metode statistik non parametrik. Untuk menguji hubungan antara faktor-faktor pembentuk persepsi terhadap program menggunakan analisis rank spearman dan uji $T$.

$$
\mathrm{t}=r_{s} \sqrt{\frac{N-2}{1-\left(r_{s}\right)^{2}}}
$$

Keterangan :r_s = koefisien korelasi rank Spearman $\mathrm{N}=$ banyaknya sampel

$\mathrm{di}=$ selisih antara ranking dari variabel

$$
r_{s}=1-\frac{6 \sum_{i=1}^{N} d i^{2}}{N^{3}-N}
$$

Keterangan:r_s $=$ koefisien korelasi rank Spearman $\mathrm{N}$ = banyaknya sampel

Kriteria pengambilan keputusan :

1. Apabila $t$ hitung $\geq \mathrm{t}$ tabel $(\alpha=0,05)$, maka Ho ditolak. Berarti ada hubungan yang signifikan antara faktor-faktor pembentuk dengan persepsi petani program Dem Area Budidaya Tanaman Sehat Padi di Kecamatan Polokarto Kabupaten Sukoharjo.
2. Apabila $\mathrm{t}$ hitung $<\mathrm{t}$ tabel $(\alpha=0,05)$, maka Ho diterima. Berarti tidak ada hubungan antara faktor-faktor pembentuk dengan persepsi petani program Dem Area Budidaya Tanaman Sehat Padi di Kecamatan Polokarto Kabupaten Sukoharjo.

\section{HASIL DAN PEMBAHASAN}

Kecamatan Polokarto memiliki luas secara keseluruhan adalah 6.218 Ha. Memiliki luasan lahan sawah sebesar $2.453 \mathrm{Ha}$. Salah satu upaya pemanfaatan lahan sawah digunakan untuk budidaya tanaman sehat padi melalui program dem area budidaya tanaman sehat padi. Program ini dilaksanakan oleh Kelompok tani di dua desa yaitu Desa Kemasan dan Desa Bakalan. Program ini merupakan program yang bertujuan untuk memotivasi petani dalam melaksanakan budidaya tanaman sehat padi. Bentuk bantuan yang diberikan pemerintah berupa bantuan benih unggul, kapur pertanian dan juga dana yang dialokasikan untuk sarana produksi serta bimbingan teknis oleh penyuluh terkait budidaya padi sehat.

Persepsi petani terhadap suatu hal dapat dipengaruhi oleh faktor-faktor pembentuknya. Faktor-faktor pembentuk yang digunakan dalam penelitian ini adalah umur, pendidikan formal, pendidikan non formal, luas lahan, pendapatan, pengalaman dan motivasi. Tabel 1 menunjukkan distribusi skor faktor-faktor pembentuk persepsi petani terhadap program dem area budidaya tanaman sehat padi (studi kasus di Kecamatan Polokarto Kabupaten Sukoharjo).

Tabel 1 Faktor-Faktor Pembentuk Persepsi Petani Terhadap Program Dem Area Budidaya Tanaman Sehat Padi

\begin{tabular}{llcr}
\hline $\begin{array}{l}\text { Faktor - faktor } \\
\text { pembentuk persepsi }\end{array}$ & Kategori & $\begin{array}{r}\text { Responden } \\
\text { (orang) }\end{array}$ & $\begin{array}{r}\text { Persentase } \\
\text { (\%) }\end{array}$ \\
\hline Umur & $48-58$ tahun & 24 & 40,00 \\
Pendidikan Formal & Rendah (SMP/Sederajat) & 25 & 41,76 \\
Pendidikan Non Formal & Tinggi (3-4 kali/bulan) & 32 & 53,34 \\
Luas lahan & Sangat Rendah (0,26-0,50 Ha) & 27 & 45,00 \\
Pendapatan & Sangat Tinggi (>2.000.000,-/1 musim tanam) & 57 & 95,00 \\
Pengalaman & Mampu memperbaiki tingkat kehidupan (Tinggi) & 29 & 48,00 \\
Motivasi & Atas kesadaran sendiri (Sangat tinggi) & 38 & 63,33 \\
\hline
\end{tabular}

Sumber: Olahan Data Primer (2019) 
Responden dengan kelompok umur 48-58 tahun menjadi kelompok umur yang mendominasi umur responden, dapat dikatakan bahwa responden dengan umur 48-58 tahun merupakan kelompok umur lansia awal usia yang masih produktif. Umur dapat dijadikan sebagai tolak ukur dalam melihat aktivitas seseorang dalam bekerja dimana dengan kondisi umur yang masih produktif maka kemungkinan besar seseorang dapat bekerja dengan baik dan maksimal (Hasyim, 2006). Dari kalimat diatas dapat diketahuai bahwa responden sebagian besar merupakan petani yang masih berusia produktif, sehingga dari kekuatan fisik dan respon terhadap hal-hal baru relatif lebih cepat dan mudah.

Pendidikan Formal responden dapat diketahui sejumlah 25 orang $(41,76 \%)$ responden memiliki tingkat pendidikan formal rendah. Mayoritas petani dengan pendidikan yang rendah disebabkan oleh faktor sosial dan ekonomi. Pendidikan juga sangat menentukan tingkat kompetensi petani dalam melakukan kegiatan pertanian (Manyamsari \& Mujiburrahmad 2014). Kompetensi adalah perwujudan perilaku dalam merencanakan kegiatan untuk mencapai target.

Pendidikan non formal responden mayoritas adalah tinggi (3-4 kali/bulan) dimana petani dengan jumlah 32 orang atau 53,34\% mengikuti pendidikan non formal 3-4 kali dalam satu bulan. Kondisi dilapang menunjukkan bahwa petani responden aktif dalam mengikuti kegiatan penyuluhan maupun pelatihan. Baik itu penyuluhan yang bersifat terjadwal maupun penyuluhan yang bersifat swadaya.Menurut Soekartawi (1988) pengalaman pelatihan yang dimiliki seseorang (petani) akan mempengaruhi kecepatan dalam mengambil keputusan, karena dari pelatihan yang diikuti diperoleh penambahan pengetahuan dan ketrampilan dalam melakukan usahatani.

Luas lahan petani responden mayoritas sangat rendah yaitu 27 orang $(45 \%)$ responden memiliki luas lahan 0,26-0,50 Ha. Lahan petani responden merupakan lahan yang diperoleh melalui warisan orang tua dan ada juga hasil dari pembelian dan sedikit yang menyewa dengan luasan yang tidak lebar.Lahan merupakan faktor produksi yang paling penting dibandingkan dengan faktor produksi yang lain karena balas jasa yang diterima oleh lahan lebih tinggi dibandingkan dengan faktor produksi yang lain (Mubyarto dalam Hijratulloh, 2003).

Petani responden dengan pendapatan sangat tinggi dalam satu kali masa tanam berjumlah 57 orang atau 95\%. Motivasi petani dalam mencari nafkah juga merupakan faktor yang mempengaruhi pendapatan responden. Mayoritas petani responden masih memiliki motivasi mencari nafkah yang tinggi. Surati (2014) menyatakan bahwa semakin tinggi tingka pendapatan seseorang, perilakunya akan semakin bertambah/positif.

Pengalaman petani responden dengan jumlah 29 orang (48\%) adalah mampu memperbaiki tingkat kehidupan dikarenakan petani memiliki pengalaman yang mayoritas tinggi, hal ini disebabkan karena petani sangat aktif dalam kegiatan-kegiatan penyuluhan, sosialisasi dan pelatihan yang diadakan rutin maupun swadaya. Rakhmat (2005) menyatakan bahwa pengalaman mempengaruhi kecermatan persepsi. Pengalaman tidak selalu lewat proses belajar formal. Pengalaman bertambah juga melalui rangkaian peristiwa yang pernah kita hadapi.

Motivasi responden dengan kategori atas kesadaran sendiri sejumlah 38 orang $(63,3 \%)$. Petani memiliki kesadaran sendiri untuk mengikuti program dem area budidaya tanaman sehat padi. Kondisi ini menunjukkan bahwa petani telah sadar akan keinginan memperbaiki cara budidaya tanaman padi mereka untuk mendapatkan hasil yang lebih optimal. Motivasi merupakan kekuatan penggerak dalam diri seseorang untuk memaksa bertindak (Wahyuni, 2008).

\section{Persepsi Petani Terhadap Program Dem Area Budidaya Tanaman Sehat Padi}

Persepsi merupakan suatu proses di mana seseorang dapat memilih, mengatur, dan mengartikan informasi menjadi suatu gambar yang sangat berarti di dunia (Kotler, 2007). Persepsi yang dimaksud dalam penelitian ini adalah persepsi petani terhadap program dem area budidayat tanaman sehat padi yang meliputi tentang pengertian, tujuan, manfaat dan kegiatan. 
Tabel 2. Persepsi Petani Terhadap Program Dem Area Budidaya Tanamn Sehat Padi

\begin{tabular}{lcccc}
\hline \multirow{2}{*}{ Kategori } & \multicolumn{4}{c}{ Persentase (\%) } \\
\cline { 2 - 5 } & Y1 & Y2 & Y3 & Y4 \\
\hline a. Sangat Baik & 23 & 38,3 & 33,3 & 40,0 \\
b. Baik & 30 & 50,0 & 60,0 & 41,7 \\
c. Kurang Baik & 7 & 11,7 & 6,7 & 18,3 \\
d. Sangat Tidak Baik & 0 & 0 & 0 & 0 \\
\hline Jumlah & $\mathbf{1 0 0 , 0}$ & $\mathbf{1 0 0 , 0}$ & $\mathbf{1 0 0 , 0}$ & $\mathbf{1 0 0 , 0}$ \\
\hline
\end{tabular}

Sumber: Olahan Data Primer 2019

Keterangan:

Y1 : Persepsi petani terhadap pengertian program

Y2 : Persepsi petani terhadap tujuan program

Y3 : Persepsi petani terhadap manfaat program

Y4 : Persepsi petani terhadap pelaksanaan program

Berdasarkan Tabel 2 persepsi petani terhadap pengertian program dem area budidaya tanaman sehat padi adalah baik yaitu sebanyak 39 orang (30\%). Responden yang memiliki persepsi baik merupakan responden yang merasa puas dengan kegiatan sosialisasi yang dilakukan oleh pihak-pihak yang memberikan informasi yaitu, Dinas Pertanian Kabupaten Sukoharjo dan Balai Penyuluh Pertanian Kecamatan Polokarto. Persepsi termasuk dalam salah satu komponen dari kognitif yang berisi kepercayaan seseorang mengenai apa yang berlaku (Hendayana, 2014).

Persepsi petani terhadap tujuan program dengan kategori baik berjumlah 30 orang atau $(50 \%)$ hal ini berarti bahwa tujuan program dem area budidaya tanaman sehat padi pada umumnya sesuai dengan apa yang diharapkan petani. Program dem area budidaya tanamn sehat padi bertujuan untuk dapat menjadi contoh budidaya tanaman sehat padi, dapat menamggulangi serangan OPT yang terjadi, mampu meningkatkan produktivitas padi. Menurut Davis (1989) sejauh mana individu percaya terhadap suatu sistem tertentu makan akan meningkatkan kinerja pekerjaannya.

Persepsi petani kategori baik terhadap manfaat program dem area budidaya tanaman sehat berjumlah 36 orang $(60 \%)$ menandakan bahwa program dem area budidaya tanaman sehat padi cukup memberikan banyak manfaat bagi petani.Manfaat ini dapat dilihat melalui besarnya

peran kegiatan program dem area budidaya tanaman sehat padi dalam memperbaiki tingkat kehidupan petani dengan hasil produksi padi yang meningkat. Petani yang mempunyai kemampuan mempertimbangkan sesuatu dari segala aspek berkaitan dengan keberlanjutan usahataninya maka cenderung menilai sesuatu program yang diintroduksikan pada kategori yang tinggi dan mudah untuk diimplementasikan (Suharyanto, 2017).

Persepsi petani terhadap kegiatan program dem area budidaya tanaman sehat padi dapat diketahui bahwa responden dengan tingkat persepsi baik sejumlah 25 orang $(41,7 \%)$. Umumnya petani mengetahui apa saja kegiatan dari program dem area budidaya tanaman sehat padi. Kegiatan program dem area budidaya tanaman sehat padi meliputi sosialisasi, bimbingan teknis lapang, pendampingan, dan evaluasi.

\section{Hubungan antara Faktor-Faktor Pembentuk Persepsi dengan Persepsi Petani terhadap Program Dem Area Budidaya Tanaman Sehat Padi}

Hasil analisis hubungan antara faktorfaktor Pembentuk Persepsi dengan Persepsi petani terhadap program dem area budidaya tanaman sehat padi dapat dilihat pada tabel 3 sebagai berikut: 
Tabel 3. Hubungan Antara Faktor-Faktor Pembentuk Persepsi Dengan Persepsi Petani Terhadap Program

\begin{tabular}{lrrr}
\hline \multirow{2}{*}{ Faktor yang Mempengaruhi Persepsi (X) } & \multicolumn{2}{c}{ Persepsi Total (Ytot) } & \multirow{2}{*}{ Keterangan } \\
\cline { 2 - 3 } & \multicolumn{1}{c}{$\mathbf{r}_{\mathrm{s}}$} & \multicolumn{1}{c}{ T hitung } & \\
\hline Umur (X1) & $-0,113$ & $-0,866$ & Tidak signifikan \\
Pendidikan formal (X2) & 0,014 & 0,107 & Tidak signifikan \\
Pendidikan non formal (X3) & $-0,02$ & $-0,152$ & Tidak signifikan \\
Luas lahan (X4) & 0,137 & 1,053 & Tidak signifikan \\
Pendapatan (X5) & 0,286 & 2,273 & Signifikan \\
Pengalaman (X6) & 0,273 & 2,161 & Signifikan \\
Motivasi (X7) & 0,129 & 0,991 & Tidak signifikan \\
\hline
\end{tabular}

Sumber: Olahan Data Primer 2019

Berdasarkan Tabel 3 tidak terdapat hubungan yang signifikan antara umur dengan persepsi petani terhadap program dem area budidaya tanaman sehat padi studi kasus di Kecamatan Polokarto Kabupaten Sukoharjo pada tingkat kepercayaan 95\%. Hubungan yang tidak signifikan antara umur dengan persepsi tidak sesuai dengan teori Ehrenberg dan Smith (1988) bahwa Umur petani mempengaruhi kemampuan fisik bekerja dan cara berpikir. Petani yang berusia lebih tua di Kecamatan Polokarto Kabupaten Sukoharjo belum tentu memiliki persepsi yang buruk terhadap program dem area budidaya tanaman sehat padi. Petani dengan usia yang tua lebih aktif dalam mencari informasi baik kepada penyuluh maupun kepada kelompok.

Tidak terdapat hubungan yang signifikan antara pendidikan formal dengan persepsi petani terhadap program dem area budidaya tanaman sehat padi studi kasus di Kecamatan Polokarto Kabupaten Sukoharjo pada tingkat kepercayaan $95 \%$. Hal ini tidak sesuai dengan pernyataan Tomy, (2013) bahwa pendidikan yang relatif tinggi dan umur muda menyebabkan petani lebih dinamis, tingginya tingkat pendidikan petani sangat terkait dengan daya nalar petani dalam menerima penyuluhan dari PPL (Penyuluh Pertanian Lapangan). Tinggi rendahnya pendidikan formal responden tidak berhubungan nyata dengan persepsi petani, pengetahuan dan informasi yang diperoleh responden didapatkan melalui kegiatan yang bukan berasal dari pendidikan formal, responden memperoleh pengetahuan dari pendidikan nonformal seperti kegiatan penyuluhan.

Hubungan antara pendidikan non formal dengan Persepsi petani terhadap program dem area budidaya tanaman sehat padi studi kasus di Kecamatan Polokarto Kabupaten Sukoharjo pada tingkat kepercayaan 95\% adalah tidak signifikan. Demikian ini tidak sesuai dengan pernyataan Soekartawi (1988) pengalaman pelatihan yang dimiliki seseorang (petani) akan mempengaruhi kecepatan dalam mengambil keputusan. Pendidikan non formal pada program dem area budidaya tanaman sehat padi hanya berupa sosialisasi dan penyuluhan saja, yang dilakukan hanya 1 kali dalam satu bulan.

Tidak terdapat hubungan yang signifikan antara luasan lahan dengan persepsi petani terhadap program dem area budidaya tanaman sehat padi studi kasus di Kecamatan Polokarto Kabupaten Sukoharjo pada tingkat kepercayaan 95\%. Sejalan dengan penelitian Widiyastuti (2016) menyatakan petani dalam melaksanakan usahatani tidak melihat seberapa luas lahan yang dimiliki melainkan risiko apa yang akan terjadi apabila menggunakan inovasi teknologi baru yang sebelumnya belum pernah dilakukan ataupun sudah dilakukan namun masih mengalami kegagalan dalam usahatani yang dilakukan.

Terdapat hubungan yang signifikan antara pendapatan dengan persepsi petani terhadap program dem area budidaya tanaman sehat padi studi kasus di Kecamatan Polokarto Kabupaten Sukoharjo pada tingkat kepercayaan 95\%. Sejalan dengan pernyataan Soekartawi (1988) bahwa karakteristik seseorang juga mempengaruhi persepsi seseorang diantaranya faktor situasi yaitu pendapatan usaha tani, status kepemilikan tanah, ukuran usaha tani, sumber informasi yang digunakan, prestise masyarakat. 
Hubungan antara pengalaman dengan program dem area budidaya tanaman sehat padi adalah signifikan pada tingkat kepercayaan $95 \%$. Hal ini sejalan dengan Rakhmat, (2000) persepsi seperti juga sensasi yang ditentukan oleh faktor personal dan faktor situasional. Pengalaman personal diantaranya, pengalaman yang tidak didapatkan dengan pendididkan formal.

Tidak terdapat hubungan yang signifikan antara motivasi dengan persepsi petani terhadap program dem area budidaya tanaman sehat padi studi kasus di Kecamatan Polokarto Kabupaten Sukoharjo pada tingkat kepercayaan 95\%. Hubungan yang tidak signifikan antara motivasi dengan persepsi tidak sesuai dengan pernyataan Rakhmat, (2000) bahwa persepsi seperti juga sensasi yang ditentukan oleh faktor personal dan faktor situasional.

\section{KESIMPULAN DAN SARAN}

\section{Kesimpulan}

Berdasarkan hasil analisis dan pembahasan dapat disimpulkan bahwa, persepsi petani terhadap program dem area budidaya tanaman sehat padi (studi kasus di Kecamatan Polokarto Kabupaten Sukoharjo) adalah baik. Petani bersedia mendukung dan menerapkan program dem area budidaya tanaman sehat padi karena program dinilai positif dan banyak manfaat yang bisa dirasakan bagi para petani.

Karakteristik faktor-faktor pembentuk persepsi, umur petani responden termasuk kedalam lansial awal yang sebagian besar berusia 48-58 tahun, pendidikan formal petani responden berada pada tingkat rendah yaitu sebagian besar menamatkan pendidikan sampai SMP, pendidikan non formal petani responden termasuk kedalam kategori yang tinggi, petani sering mengikuti kegiatan sosialisasi dan pelatihan yang diadakan, luas lahan petani responden termasuk kedalam kepemilikan yang sangat rendah yaitu 0,26-0,50 Ha, pendapatan petani responden termasuk kedalam kategori sangat tinggi yaitu $>$ Rp. 2.000.000,00 setiap satu kali masa tanam, pengalaman petani responden dalam melakukan program dem area budidaya tanaman sehat padi termasuk kedalam kategori tinggi yaitu mampu memeperbaiki tingkat kehidupan petani, motivasi petani responden dalam melaksanakan program dem area budidaya tanaman sehat padi adalah sangat tinggi yaitu atas kesadaran sendiri.

Hubungan antara faktor-faktor pembentuk persepsi dengan persepsi petani terhadap program dem area budidaya tanaman sehat padi : faktor pendapatan dan faktor pengalaman berhubungan signifikan terhadap persepsi petani terhadap program dem area budidaya tanaman sehat padi. Faktor umur, faktor pendidikan formal dan faktor pendidikan non formal, faktor luas lahan, dan faktor motivasi tidak berhubungan signifikan terhadap persepsi petani terhadap program dem area budidaya tanaman sehat padi.

\section{Saran}

Petani diharapkan dapat terus mendukung dan melaksanakan atau menerapkan program dem area budidaya tanaman sehat padi serta terlibat aktif dalam percontohan kepada petani yang lain. Penyuluh selaku fasilitator diharapkan terus mendampingi petani dalam melaksanakan budidaya tanaman sehat padi secara terus menerus agar motivasi petani terus meningkat.

Dinas Pertanian, pemerintah maupun instansi terkait diharapkan dapat terus mempertahankan serta meningkatkan antusiasme petani terkait pelaksanaan budidaya tanaman sehat padi dengan cara mengadakan kegiatan sosialisasi, diskusi maupun pelatihan secara rutin dan berkala sehingga dapat menambah wawasan petani.

\section{DAFTAR PUSTAKA}

Crandell, T.L., Crandell, C.H., Zanden, J.W.V. (2012). Human Development (Tenth Edition). Americas: Mc Graw-Hill.

Davis FD. 1989. Perceived usefulness, perceived ease of use, and user acceptance of information technology. MIS Quarterly. 13(3):319-339.

Ehrenberg, R.G dan Smith, R.S. 1988. Modern Labor Economics: Theory and Public Policy. London:Scoot,Foresman Company.

Hasyim, Hasman. 2006. Analisis Hubungan karakteristik petani kopi terhadap pendapatan ( studi kasus : Desa dolok saribu Kecamatan Paguran Kabupaten Tapanuli utara . Jurnal komunikasi penelitian $\operatorname{Vol}(1)$. 
Rachmat Hendayana. 2014. Persepsi dan Adopsi Teknologi. Modul dalam kegiatan Peningkatan Kapasitas Sumberdaya Peneliti Sosial Ekonomi Dalam Analisis Sosial Ekonomi dan Kebijakan Pertanian. Bogor.

Kotler, Philip. 2007. Manajemen Pemasaran, Jilid 2, Edisi 12. PT Indeks: New Jersey

Manyamsari I, Mujiburrahmad. 2014. Karakteristik Petani Dan Hubungannya Dengan Kompetensi Petani Lahan Sempit (Kasus : Di Desa Sinar Sari Kecamatan Dramaga Kab. Bogor Jawa Barat). J Agrisep Vol (15) No. 2

Mubyarto. 2003. Pengantar Ekonomi Pertanian. Jakarta: LP3ES.

Putra,E.2018. Surplus Beras 135.335 Ton di 2017, Sukoharjo Tertinggi se-Jateng. https:// sukoharjonews.com/pemerintahan/surplusberas-135-335-ton-di-2017-sukoharjotertinggi-se-jateng/

Rahkmat, J. 2000. Psikologi Komunikasi. Edisi Revisi. Bandung: PT Remaja Rosdakarya. 2005. Psikologi Komunikasi, edisi revisi. Bandung: Remaja Rosdakarya.

Soekartawi, 1988. Prinsip dasar Komunikasi Pertanian. Jakarta: Universitas Indonesia.

Suharyanto1, Jemmy Rinaldi2, Nyoman Ngurah Arya2 dan Ketut Mahaputra2 . 2017. FaktorFaktor Yang Mempengaruhi Persepsi Petani Terhadap Kebijakan Perlindungan Lahan Pertanian Pangan Berkelanjutan Di Provinsi Bali. Jurnal Pengkajian dan Pengembangan Teknologi Pertanian (JPPTP) Vol 20 (2).

Surati. (2014). Analisis sikap dan perilaku masyarakat terhadap Hutan Penelitian Parung Panjang. Jurnal Penelitian Sosial dan Ekonomi Kehutanan, Vol 11(4), 339347.

Suryana, A. 2002. World Food Summit: Aliansi internasional mengikis kelaparan.Kompas, 18 Juni 2002.

Tomy J. 2013. Faktor-Faktor Yang Mempengaruhi Produksi Usahatani Jagung Di Kecamatan Sindue Kabupaten Donggala. J. Agroland 17 (3) : $61-66$
Van den Ban \& Hawkins. 1999. Penyuluhan Pertanian. Penerbit. Yogyakarta: PT. Kanisius.

Wahyuni, Dewi Urip. 2008. Pengaruh Motivasi, Persepsi dan Sikap Konsumen Terhadap Keputusan Pembelian Sepeda Motor Merek "Honda" di Kawasan Surabaya Barat. Jurnal Manajemen dan Kewirausahaan Vol $10(1): 30$.

Widiyastuti, Emi Widiyanti, Sutarto. 2016. Persepsi Petani Terhadap Pengembangan System Of Rice Intensification (Sri) Di Kecamatan Moga Kabupaten Pemalang. $J$ AGRISTA : Vol. 4(3). 